\title{
A produção científica sobre permanência e evasão na educação superior no Brasil
}

\author{
Carina Elisabeth Maciel ${ }^{1}$ \\ ORCID: 0000-0003-3765-3139 \\ Mauro Cunha Júnior ${ }^{1}$ \\ ORCID: 0000-0002-6906-7786 \\ Tatiane da Silva Lima ${ }^{1}$ \\ ORCID: 0000-0002-7472-500X
}

\section{Resumo}

Este artigo tem como objeto a permanência e a evasão na educação superior no Brasil. Seu objetivo é desvelar as publicações sobre permanência e evasão na educação superior divulgadas como teses, dissertações e artigos. Metodologicamente, trata-se de uma pesquisa bibliográfica, baseando-se na modalidade de pesquisa conhecida como estado da arte ou estado do conhecimento. Nesse contexto, para o levantamento da produção acadêmica, recorreu-se às bases de dados SciELO, GT 11/ANPEd, Oasisbr, Portal de Periódicos CAPES/ MEC e Domínio Público. Em síntese, em relação à permanência, foram localizadas 9 teses, 22 dissertações e 58 artigos; no caso da evasão, foram localizadas 15 teses, 75 dissertações e 122 artigos. Constata-se ainda que, quanto à permanência, os estudos concentram-se nas temáticas permanência e EaD, permanência e ProUni e permanência e estudantes com deficiência; no caso da evasão, os trabalhos estão concentrados em evasão em um conjunto de cursos, evasão na EaD e evasão em um curso de uma instituição especifica. Além disso, evidencia-se que os trabalhos sobre permanência tiveram início a partir de 2004, com um crescimento significativo entre os anos de 2012 e 2016; no que diz respeito à evasão, verifica-se que as produções tiveram início em 1977, com um crescimento exponencial entre os anos de 2011 e 2014. Em relação às instituições onde as pesquisas foram realizadas, a região Sul do Brasil concentra o número de produções mais significativo acerca dessas temáticas. Por fım, nota-se que o número de cooperações interinstitucionais ainda é incipiente, carecendo de mais diálogos entre instituições.

\section{Palavras-chave}

Produção científica - Permanência - Evasão - Educação superior.

1- Universidade Federal de Mato Grosso do Sul (UFMS). Campo Grande, MS, Brasil. Contatos: carina22em@gmail.com; mauro.junior6@hotmail. com; tati_lima09@hotmail.com. 


\section{The scientific production on permanence and dropout in higher education in Brazil}

\section{Abstract}

The scope of this article is the permanence and dropout in higher education in Brazil. Its objective is to unveil the publications on permanence and dropout in higher education published as theses, dissertations, and articles. Methodologically, this is a bibliographical research, based on a modality known as state of art or state of knowledge. In this context, for the survey of academic production, we used the databases SciELO, GT 11 / ANPEd, Oasisbr, Portal of Periodicals CAPES/MEC and Public Domain. In summary, in relation to permanence, 9 theses, 22 dissertations, and 58 articles were located; in the case of dropout, 15 theses, 75 dissertations, and 122 articles were located. Regarding permanence, we observed that the studies focus on the following topics: permanence and $\mathrm{EaD}$, permanence and ProUni, and permanence and students with disabilities; for dropout, works address mainly dropout in a set of courses, dropout in EaD, and dropout in a course of a specific institution. In addition, it is evident that research on permanence began as of 2004, with a significant growth between 2012 and 2016; in terms of dropout, production began in 1977, with an exponential increase between 2011 and 2014. In relation to the institutions where the research was carried out, the southern region of Brazil has most and the more significant productions concerning these issues. Finally, it is noted that the number of interinstitutional cooperation is still incipient so the dialogue between institutions needs to be enhanced.

\section{Keywords}

Scientific production - Permanence - Dropout - Higher education.

\section{Introdução}

Este artigo tem como objeto a permanência e a evasão na educação superior no Brasil. Seu objetivo é desvelar as publicações sobre permanência e evasão na educação superior divulgadas como teses de doutorado, dissertações de mestrado e artigos. Essas publicações representam os resultados de pesquisas sobre tais temáticas no país. Para tanto, a quantidade de produtos identificados, o ano em que as produções foram desenvolvidas e a identificação das instituições onde as pesquisas foram realizadas expressam a importância destinada ao tema no país.

A justificativa para a produção deste trabalho insere-se dentro do quadro de expansão da educação superior brasileira. Convém ressaltar que, no Brasil, houve a 
ampliação do número de instituições e vagas ofertadas na educação superior. ${ }^{2}$ Nesse contexto, demandou-se a criação de políticas públicas que não apenas viabilizassem a expansão e o acesso à educação superior, mas que garantissem condições de permanência de estudantes dentro dessas instituições. Assim, nos últimos anos, mais especificamente a partir de 2011, as produções científicas sobre permanência e evasão vêm adquirindo relevância no processo de consolidação do sistema de educação superior, uma vez que cooperam na busca de elementos no combate à evasão e no fortalecimento das ações de permanência. No mesmo movimento é possível identificar como a temática se materializa por meio das produções científicas.

Para tanto, nesta pesquisa buscamos quantificar as produções existentes acerca da permanência e da evasão na educação superior, compreender quais foram os temas de maior relevância e discussão nessas pesquisas e identificar quais são as instituições que têm se voltado para a temática, além de ressaltar o alcance dos estudos desenvolvidos num determinado período de tempo, pois reconhecemos que,

Nessa perspectiva, fazer um balanço sobre o estado do conhecimento numa determinada área é uma necessidade premente para qualquer setor de pesquisa, já que o crescimento quantitativo não pode ser tomado isoladamente como critério de avanço no campo de investigação, qualquer que seja ele. (SANTOS, F., 2014, p. 20).

Por conseguinte, metodologicamente, nosso estudo trata-se de uma pesquisa bibliográfica, baseando-se na modalidade de pesquisa conhecida como estado da arte ou estado do conhecimento, que, segundo Ferreira (2002, p. 258), pode ser definida como

[...] de caráter bibliográfico, elas parecem trazer em comum o desafıo de mapear e de discutir uma certa produção acadêmica em diferentes campos do conhecimento, tentando responder que aspectos e dimensões vêm sendo destacados e privilegiados em diferentes épocas e lugares, de que formas e em que condições têm sido produzidas certas dissertações de mestrado, teses de doutorado, publicações em periódicos e comunicações em anais de congressos e de seminários.

Para o levantamento da produção acadêmica acerca do objeto deste estudo, recorreu-se às bases de dados do Scientific Electronic Library Online (SciELO), Grupo de Trabalho Políticas de Educação Superior - GT 11 da Associação Nacional de Pós-Graduação e Pesquisa em Educação (ANPEd), Portal brasileiro de publicações científicas em acesso aberto (Oasisbr), Portal de Periódicos CAPES/MEC e Domínio Público.

Cabe destacar que o levantamento do material bibliográfico foi realizado durante os meses de julho a novembro de 2017. Nesse contexto, com a finalidade de delimitar o

\footnotetext{
2- Segundo os dados do Instituto Nacional de Estudos e Pesquisas Educacionais Anísio Teixeira (INEP), coletados a partir do Censo da Educação Superior (1995-2017), em 1995, o Brasil apresentava um total de 894 Instituições de Ensino Superior (IES), sendo 210 (23,5\%) instituições públicas e 684 (76,5\%) privadas. Já em 2017, das 2.448 IES, 296 (12,1\%) eram públicas e 2.152 (87,9\%) privadas. Em relação ao número de vagas em cursos de graduação presencial nessas instituições, os dados do Inep evidenciaram que, de 1995 a 2017, 0 quantitativo de vagas passou de 610.355 para 3.857.572, proporcionando um aumento percentual de 532,0\%. Nesse contexto, o setor privado se sobressaiu, com um crescimento de 670,8\%, enquanto no setor público esse acréscimo correspondeu a 195,3\%.
} 
campo das produções acadêmicas, fizemos buscas com as palavras-chave ${ }^{3}$ permanência e educação superior; depois, com permanência e ensino superior. Já para fazer a busca por produções referentes à evasão, utilizamos as palavras-chave evasão e educação superior; depois, evasão e ensino superior. A Lei de Diretrizes e Bases da Educação Nacional, de 1996, em seu artigo 21, apresenta a educação nacional em dois níveis: educação básica e educação superior. Entretanto, muitos autores ainda utilizam o termo ensino superior, assim, optamos por realizar a pesquisa com os dois termos em questão.

0 objetivo foi selecionar produções escritas em língua portuguesa que dialogassem com a temática permanência e com a temática evasão de alunas/os na educação superior. Além disso, ressaltamos que, para as procuras, não houve limitação à área de educação, assim como não houve delimitação temporal para a seleção das produções acadêmicas.

Em termos de organização, o artigo está estruturado em duas partes, além da introdução e das considerações finais. Na primeira seção, por meio de uma abordagem qualitativa, propõe-se a analisar os aspectos conceituais de permanência e de evasão na educação superior. Na segunda seção, apresentamos os resultados analisados nesta pesquisa. Nesse sentido, destacamos o número de produções, as categorias/vertentes temáticas que se relacionam com permanência e evasão, a distribuição do número de produções por ano e, por último, os vínculos institucionais das/os autoras/es das pesquisas.

\section{Aspectos conceituais de permanência e evasão nas pesquisas nacionais}

A partir do material selecionado e com base numa abordagem qualitativa ${ }^{4}$, apresentaremos os conceitos de permanência e evasão presentes em algumas das produções nacionais, dado que nem todas as produções lidas trazem tais definições. Após uma primeira aproximação com o material bibliográfico, por meio da leitura dos resumos, foi realizada posteriormente uma leitura mais minuciosa, a fim de delinear os conceitos e as definições apresentados acerca do nosso objeto, de modo que possamos expor e refletir como a permanência e a evasão na educação superior têm sido abordadas.

Para definir o conceito de permanência, Bueno (2015) constata que, no Brasil, os estudos que tratam sobre a permanência estudantil na educação superior pública utilizam os termos assistência e permanência, "visto que, os entendem como demandas distintas e que se apoiam para auxiliar o estudante durante sua trajetória acadêmica” (BUENO, 2015, p. 14). Já Tibola (2010) utiliza em seus estudos o termo permanência atrelado à retenção, pois em suas pesquisas ficou evidenciado que estes têm sido empregados conjuntamente.

Assim como Tibola (2010), Fiuza e Sarriera (2013, p. 886) tratam permanência e retenção como sinônimas e definem que "retenção/permanência é a continuada

\footnotetext{
3- No site da ANPEd não há um mecanismo de busca por palavras-chave de todos os trabalhos já apresentados. Assim, para procurarmos por trabalhos que discutem nosso tema em questão, buscamos no Grupo de Trabalho 11 - Política de Educação Superior nas páginas de cada reunião anual da ANPEd (38 reuniões, ao todo) por trabalhos que tivessem escrito educação/ensino superior, permanência e evasão no título e/ ou nas palavras-chave.

4- Para Minayo (2016), a pesquisa qualitativa responde a questões muito particulares. Ela se ocupa, dentro das Ciências Sociais, com o universo dos significados, dos motivos, das aspirações, das crenças, dos valores e das atitudes.
} 
participação dos estudantes em um evento de aprendizagem para conclusão, que, no ensino superior, poderia ser um curso, programa, disciplina ou sistema”.

As autoras Sena (2011), Marianna Santos (2014), Lavarda (2014) e Cavalcante (2008) entendem a permanência nas Instituições de Ensino Superior (IES) como a ação de permanecer e concluir os estudos, enfrentando obstáculos e dificuldades que possam ter surgido ao longo do caminho. Marianna Santos (2014), corroborando os estudos de Zago (2006), Coulon (2008) e Santos (2009), complementa que, para que haja permanência e finalização do curso, é preciso levar em conta as demandas materiais, tais como transporte, alimentação e material didático, além da dimensão simbólica, que é referente à identificação e ao pertencimento ao grupo.

Essas demandas, tanto materiais quanto simbólicas, também estão presentes nos estudos de Passos (2015), que as relacionam com a permanência, pois são tais demandas que permitem às/aos estudantes cotistas se manterem na IES de acordo com o período adequado à sua formação. Silva (2012) ainda considera que a permanência tem de estar relacionada à situação em que a/o estudante mantém a motivação, encontrando condições que considera essenciais para permanecer no curso de graduação.

No que diz respeito ao conceito ou definição de evasão, a literatura nacional apresenta diferentes significados. Bueno (1993, p. 13) ressalta que "a evasão pode estar significando uma postura ativa do aluno que decide desligar-se por sua própria responsabilidade”. Para Braga, Miranda-Pinto e Cardeal (1997, p. 438), "a evasão se caracteriza quando o estudante deixa o curso antes de se graduar".

Polydoro (2000), Bardagi (2007), Adachi (2009, 2017), Mello e Santos (2012), Palma (2007) e Silva (2009) definem evasão a partir do estudo realizado pela Comissão Especial de Estudos sobre a Evasão nas Universidades Públicas Brasileiras (BRASIL, 1996). Nessa pesquisa, a evasão é caracterizada da seguinte maneira: evasão de curso, quando a/o estudante desliga-se de seu curso superior sem concluí-lo; evasão da instituição, quando a/o estudante desliga-se da instituição na qual está matriculada/o; e, por último, evasão do sistema, quando a/o estudante abandona de forma definitiva ou temporária a educação superior.

Outras pesquisas definem evasão como não finalização do curso em que a/o aluna/o estava matriculada/o (SCALI, 2009); saída da/o aluna/o da instituição antes da conclusão do seu curso (BAGGI; LOPES, 2011); fenômeno educacional complexo que ocorre em todos os tipos de instituição de ensino e afeta o sistema educacional como um todo (MOROSINI et al., 2012); processo de interrupção intencional no ciclo de estudos (BARLEM et al., 2012); perda de parte do corpo discente durante o ciclo de estudos (PEREIRA JÚNIOR, 2012); e não finalização de um percurso de formação iniciado (FREITAS, 2016).

É importante destacar que a permanência e a evasão representam elementos de trajetórias acadêmicas, mas dissociados para fins de pesquisa. A identificação do conceito de permanência é um dos aspectos entendidos como basilares para que o acesso se realize como ingresso, permanência e conclusão (MACIEL; LIMA; GIMENEZ, 2016). A evasão representa o desligamento do curso ou da instituição e interfere no rompimento do acesso a esse nível de educação.

Diante do que foi exposto, verificamos que muitas são as compreensões adotadas por pesquisadoras/es e estudiosas/os na área da educação superior acerca do conceito/definição de permanência e de evasão. Com a finalidade de delinear algumas questões em torno 
dessas temáticas, na próxima seção apresentamos os resultados quantitativos analisados nesta pesquisa. Nesse sentido, destacamos o número de produções, as categorias/vertentes temáticas que se relacionam com permanência e evasão, a distribuição do número de produções por ano e, por último, os vínculos institucionais das/os autoras/es das pesquisas.

\section{Permanência e evasão nas publicações nacionais}

Após o download dos trabalhos selecionados, considerando as cinco bases de dados já ressaltadas na introdução deste trabalho, contabilizamos 69 artigos, 23 dissertações de mestrado e 9 teses de doutorado pertinentes à permanência na educação superior. Após essa seleção, relemos todos os títulos e desconsideramos as produções que estavam repetidas, por terem sido encontradas em mais de uma base de dados; como resultado, têm-se 9 teses de doutorado, 22 dissertações de mestrado e 58 artigos, totalizando 89 produções. Pertinentes à evasão na educação superior, também considerando as cinco bases de dados e desconsiderando os trabalhos repetidos, contabilizamos 15 teses de doutorado, 75 dissertações de mestrado e 122 artigos, totalizando 212 produções.

0 Gráfico 1 ilustra o quantitativo de produções encontradas e que estão relacionadas à permanência e à evasão na educação superior.

Gráfico 1 - Quantidade de produções encontradas relacionadas à permanência e à evasão na educação superior

$$
\text { • Permanência Evasão }
$$

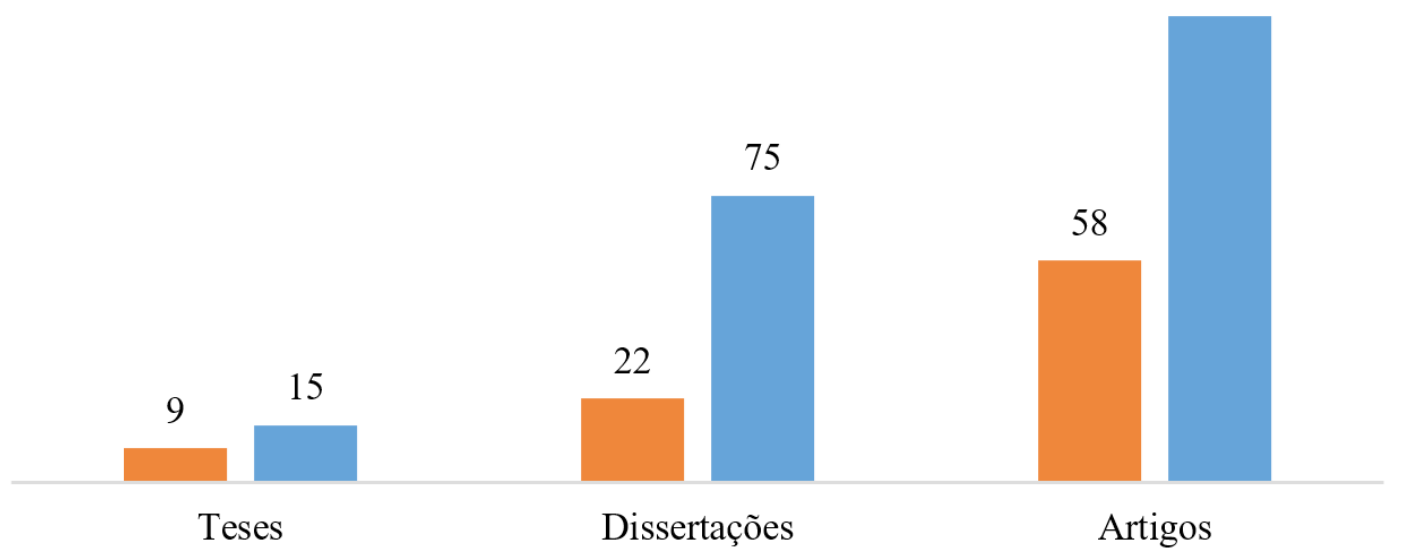

Fonte: SciELO, Grupo de Trabalho 11 da ANPEd, Oasisbr, CAPES/MEC e Domínio Público.

Feita a análise das produções acadêmicas, foi possível categorizar os trabalhos de acordo com o enfoque do estudo. Entretanto, verificou-se que alguns trabalhos tratavam 
de mais de uma temática categorizada. Nesses casos, procedeu-se a seleção do principal tema abordado para a inclusão nas tabelas.

Desse modo, as Tabelas 1 e 2 explicitam as categorias/vertentes temáticas sobre permanência e evasão na educação superior.

Tabela 1 - Estudos com a temática permanência na educação superior

\begin{tabular}{|c|c|c|c|c|c|c|}
\hline Tema abordado & Teses & $\%$ & Dissertações & $\%$ & Artigos & $\%$ \\
\hline Permanência e cotas raciais & 1 & 11,1 & 1 & 4,6 & 6 & 10,3 \\
\hline Permanência e ações afirmativas & - & - & 2 & 9,0 & 6 & 10,3 \\
\hline Permanência e estudantes com deficiência & 1 & 11,1 & 5 & 23,0 & 18 & 31,0 \\
\hline Permanência e EaD & 2 & 22,2 & - & - & 3 & 5,2 \\
\hline Permanência e avaliação da permanência & 1 & 11,1 & 2 & 9,0 & 4 & 7,0 \\
\hline Permanência e estudantes indígenas & - & - & 1 & 4,6 & 4 & 7,0 \\
\hline Permanência e ProUni & 2 & 22,2 & 1 & 4,6 & 6 & 10,3 \\
\hline Permanência e desigualdade racial & 1 & 11,1 & - & - & 1 & 1,7 \\
\hline Permanência e estudantes cotistas & 1 & 11,1 & 2 & 9,0 & 1 & 1,7 \\
\hline Permanência e camadas populares & - & - & 1 & 4,6 & 3 & 5,2 \\
\hline Permanência e acesso à educação superior & - & - & - & - & 1 & 1,7 \\
\hline Permanência e estudantes negras/os & - & - & 1 & 4,6 & 2 & 3,5 \\
\hline Permanência e escola pública & - & - & 3 & 13,6 & 1 & 1,7 \\
\hline Permanência e curso superior noturno & - & - & 2 & 9,0 & 1 & 1,7 \\
\hline Permanência, maternidade e trabalho & - & - & 1 & 4,6 & - & - \\
\hline Permanência e permanência prolongada & - & - & - & - & 1 & 1,7 \\
\hline Total & 9 & 100 & 22 & 100 & 58 & 100 \\
\hline
\end{tabular}

Fonte: Elaborada pelas/os autoras/es a partir de SciELO, ANPEd, Oasisbr, CAPES e Domínio Público.

A Tabela 1 é pertinente às produções que discutem permanência na educação superior. Dessa maneira, foram levantadas 16 categorias. Em relação às teses, nota-se 
que as produções acadêmicas se concentram em questões como permanência e EaD e permanência e ProUni, apresentando ambas dois (22,2\%) trabalhos. No caso das dissertações, a temática que tem maior discussão está relacionada à permanência e a estudantes com deficiência, com cerca de cinco (23,0\%) produções. No que concerne aos artigos, verificamos que, assim como no caso das dissertações, a temática permanência e estudantes com deficiência é a mais discutida, com um total de 18 (31,0\%) produções.

Convém destacar, a título de exemplo, que a tese de Silva (2012) identifica as variáveis que interferem no processo de permanência das/os alunas/os de Administração da Universidade Estadual do Maranhão (UEMA), comparando as modalidades presencial e a distância. Como resultado, o autor ressalta que a interação social, principalmente com os docentes, influencia positivamente na permanência de estudantes, tanto no curso $\mathrm{EaD}$ quanto no curso presencial, incentivando-as/os a concluírem seus cursos no tempo regular da graduação.

Referente às pesquisas cuja temática relaciona permanência e ProUni, a tese de Sena (2011) merece destaque, pois, visando identificar as ações pessoais, institucionais e políticas que podem contribuir na permanência de bolsistas ProUni, priorizando as falas e vivências de nove estudantes trabalhadoras/es do curso noturno de Pedagogia em três instituições universitárias de Minas Gerais, sua pesquisa mostrou que somente o esforço pessoal da/o aluna/o a/o mantém na educação superior, dado que o ProUni viabiliza somente o ingresso, carecendo de políticas públicas que estimulem a permanência.

Já a dissertação de Branco (2015), cuja finalidade foi analisar os suportes e as barreiras de acessibilidade encontradas pelas/os estudantes com deficiência na educação superior de pós-graduação da Universidade Estadual Paulista (UNESP), por meio de entrevistas com cinco estudantes, pôde notar a presença de mudanças para as remoções de barreiras arquitetônicas, que visa contribuir na inserção de estudantes com deficiências físicas e/ou mobilidades reduzidas. No entanto, a autora reconhece que as unidades universitárias ainda têm desafios, tais como modificações estruturais, atitudes preconceituosas, maior apoio de âmbito metodológico, além da ausência de uma equipe de profissionais especializadas/os para o suporte educacional.

0 artigo de Castro e Almeida (2014), a fim de verificar as barreiras e os facilitadores encontrados por estudantes com deficiência no cotidiano da educação superior, teve por finalidade identificar as ações e iniciativas de universidades públicas brasileiras em relação ao ingresso e à permanência de pessoas com deficiência. Os resultados obtidos através de entrevistas semiestruturadas com 12 Coordenadores de Serviço de Apoio e 30 alunos com deficiência de 13 universidades, além de documentos oficiais, evidenciam que as universidades carecem de investimentos, tanto em ações quanto em materiais adequados e em adequação arquitetônica, no entanto, frisam que a carência maior é referente a investimentos em ações que combatam atitudes inadequadas e preconceituosas.

Nessa mesma perspectiva, a Tabela 2 diz respeito às produções que discutem evasão na educação superior. 
Tabela 2 - Estudos com a temática evasão na educação superior

\begin{tabular}{|c|c|c|c|c|c|c|}
\hline Tema abordado & Teses & $\%$ & Dissertações & $\%$ & Artigos & $\%$ \\
\hline Evasão e aspectos metodológicos & 1 & 6,7 & 5 & 6,7 & 9 & 7,4 \\
\hline Evasão e avaliação institucional & - & - & - & - & 3 & 2,5 \\
\hline Evasão e cotas & - & - & 1 & 1,3 & 3 & 2,5 \\
\hline Evasão e EaD & 2 & 13,3 & 19 & 25,3 & 22 & 18,0 \\
\hline Evasão e gestão & 1 & 6,7 & 1 & 1,3 & 4 & 3,3 \\
\hline Evasão e perfil socioeconômico & - & - & 1 & 1,3 & 2 & 1,6 \\
\hline Evasão e permanência & - & - & 2 & 2,8 & 5 & 4,1 \\
\hline Evasão e ProUni & 1 & 6,7 & 1 & 1,3 & 1 & 0,8 \\
\hline Evasão e reprovação & - & - & - & - & 1 & 0,8 \\
\hline Evasão e retenção & - & - & 3 & 4,0 & 7 & 5,7 \\
\hline Evasão e Reuni & - & - & 2 & 2,8 & 1 & 0,8 \\
\hline Evasão e revisão bibliográfica & - & - & - & - & 5 & 4,1 \\
\hline Evasão e Sisu & - & - & 1 & 1,3 & 1 & 0,8 \\
\hline Evasão e trancamento de matrícula & 1 & 6,7 & - & - & - & - \\
\hline Evasão em instituições públicas e privadas & 2 & 13,3 & - & - & 4 & 3,3 \\
\hline Evasão em um conjunto de cursos & 4 & 26,6 & 21 & 28,0 & 14 & 11,5 \\
\hline Evasão em um curso de uma instituição específica & 2 & 13,3 & 10 & 13,3 & 26 & 21,3 \\
\hline Evasão no cenário nacional & - & - & - & - & 4 & 3,3 \\
\hline Evasão no ensino superior privado & 1 & 6,7 & 7 & 9,3 & 10 & 8,2 \\
\hline Evasão e estudantes indígenas & - & - & 1 & 1,3 & - & - \\
\hline Total & 15 & 100 & 75 & 100 & 122 & 100 \\
\hline
\end{tabular}

Fonte: Elaborada pelas/os autoras/es a partir de SciELO, ANPEd, Oasisbr, CAPES e Domínio Público.

Nesse sentido, foram levantadas 20 categorias. No caso das teses, verificamos que a concentração de produções acadêmicas se dá em relação à temática evasão em um conjunto de cursos, com quatro $(26,6 \%)$ trabalhos. No que tange às dissertações, nota-se que as discussões giram em torno das vertentes evasão em um conjunto de cursos, apresentando um total de 21 (28,0\%) produções, e evasão e EaD, com 19 (25,3\%) produções. Em relação aos artigos, os dados mostram que as produções acadêmicas estão concentradas nas temáticas evasão em um curso de uma instituição específica, com cerca de 26 (21,3\%) trabalhos, e evasão na EaD, com um total de 22 (18,0\%) produções. 
Nesses estudos, por exemplo, a tese de Adachi (2017) buscou identificar a experiência universitária que favoreceu a evasão de alunos ingressantes via vestibular nos anos de 2002, 2003 e 2004, nos cursos de graduação da Universidade de São Paulo (USP), oferecidos na cidade de São Paulo, bem como em delinear os caminhos percorridos pelos jovens universitários diante dessa situação. Com relação à experiência universitária e aos caminhos percorridos pelos jovens, verificaram-se quatro perfis de trajetórias: aqueles que concluem no prazo regulamentar, ou seja, no tempo mínimo ou máximo; aqueles que evadem antes dos dois primeiros anos; aqueles que permanecem por mais de dois anos, evadem e, posteriormente, concluem, na USP, com pedidos de reingresso, ou em outra instituição de ensino; e, por último, aqueles que permanecem por mais de dois anos e não concluem a formação superior.

A dissertação de Scali (2009) procurou identificar e analisar os motivos de evasão de alunos de cursos superiores de tecnologia a partir da percepção do aluno evadido e analisar o percurso acadêmico do estudante posterior à evasão. Desse modo, os principais motivos para evasão foram: definição de curso de ingresso; localização da instituição; formação e atuação profissional do tecnólogo; condições relacionadas ao trabalho; e condições financeiras. Já em relação ao percurso acadêmico posterior à evasão, grande parte dos participantes da pesquisa já havia se graduado ou ingressado em outro curso/instituição.

Outro estudo que merece destaque é a dissertação de Silva (2017), que propôs modelos estatísticos preditivos para a gestão da evasão dos cursos de graduação ofertados a distância pela Universidade Federal de Santa Catarina (UFSC). A partir do método de Regressão Logística Binária, foram identificadas as variáveis que influenciam na evasão de cada curso, bem como foram desenvolvidos os modelos estatísticos preditivos com base nessas variáveis. A pesquisa concluiu que as variáveis que são significativas para explicar a evasão nos cursos são: o Índice de Aproveitamento Acumulado (IAA); a pontuação do aluno no vestibular; o fato de o aluno residir ou não na cidade do polo; e, por último, a idade dos estudantes.

Já o artigo produzido por Silva et al. (2012) buscou investigar os fatores que motivaram a evasão de alunos ingressantes em 2005 no curso de Licenciatura Plena em Educação Física da Universidade Federal do Piauí (UFPI). Os resultados da pesquisa revelaram que os fatores responsáveis pela evasão dos alunos foram: falta de informações sobre o curso; descontentamento com a profissão; imaturidade ao escolher o curso; pouca interação com o curso; e simultaneidade de dois cursos. Verificaram-se três situações distintas que envolvem o processo de evasão do aluno. A primeira é caracterizada pelo abandono do curso de Educação Física para concluir um segundo curso já iniciado; a segunda consiste no abandono do curso para iniciar outro; e a terceira situação caracterizase pela evasão total da educação superior.

Cabe destacar que algumas das temáticas apresentadas nas Tabelas 1 e 2 estão sendo discutidas com mais afınco por pesquisadoras/es, pois, como já ressaltado, apresentam um quantitativo significativo de produções. Entretanto, outras questões ainda carecem de mais discussões. A título de exemplo, ressaltamos, no caso da permanência: permanência e desigualdade social; permanência e acesso à educação superior, permanência e estudantes negras/os; permanência e curso superior noturno; permanência, maternidade e trabalho; e permanência e permanência prolongada. 
Em relação à evasão, enfatizamos questões como: evasão e avaliação institucional; evasão e cotas; evasão e perfil socioeconômico; evasão e ProUni, evasão e reprovação; evasão e Reuni; evasão e SISU; evasão e trancamento de matrícula; evasão no cenário nacional; e evasão e estudantes indígenas.

A seguir, no Gráfico 2, apresentamos a distribuição das produções selecionadas de acordo com os seus respectivos anos de publicação, para permanência e evasão.

Gráfico 2 - Distribuição do número das produções sobre permanência e evasão na educação superior por ano

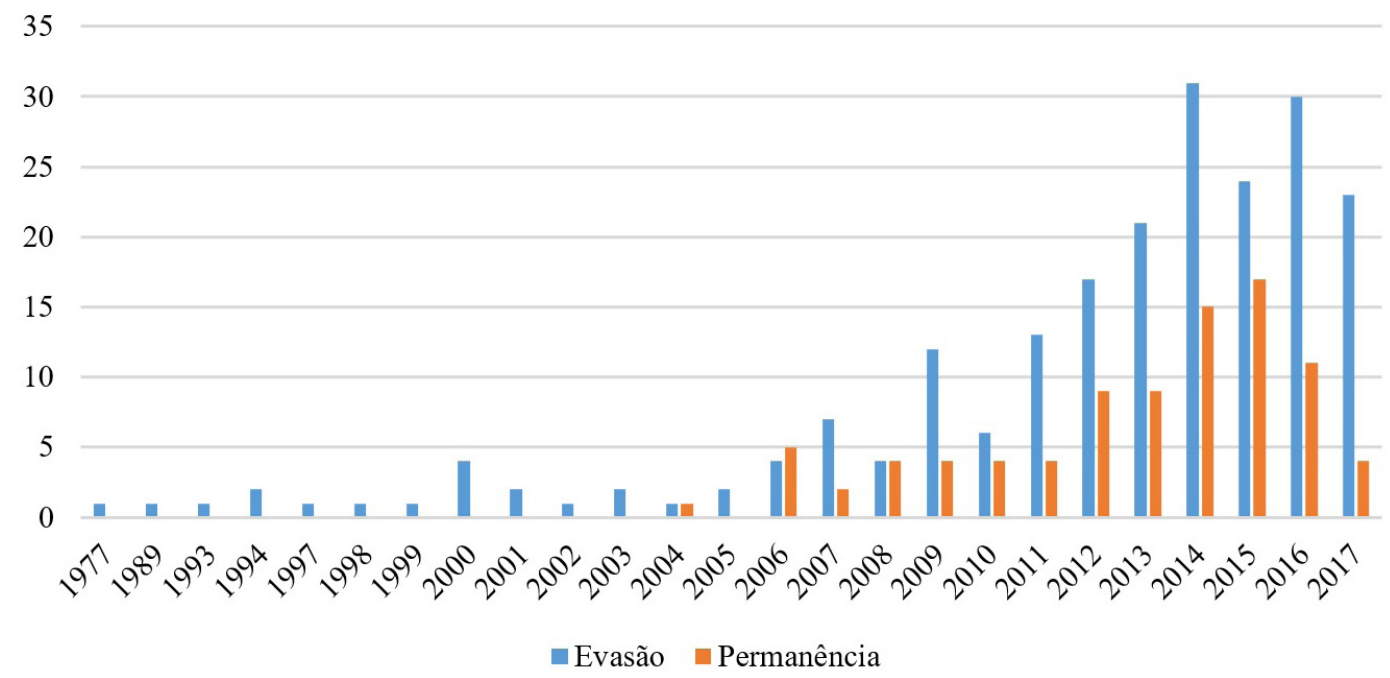

Fonte: SciELO, Grupo de Trabalho 11 da ANPEd, Oasisbr, CAPES/MEC e Domínio Público.

De acordo com os dados apresentados, nota-se que as produções acadêmicas referentes à permanência na educação superior começaram a ser discutidas a partir do ano de 2004. Nesse sentindo, verificamos que os picos de maior produção estão entre os anos de 2012 e 2016, com declínio no ano de 2017 e com maior ênfase em 2015. Em relação à evasão na educação superior, as informações apresentadas pelo Gráfico 2 evidenciaram que essa temática começou a ser discutida nas produções nacionais a partir do ano de 1977. Entretanto, o crescimento exponencial do número de trabalhos produzidos é verificado entre os anos de 2011 e 2014, com variações no triênio 2015, 2016 e 2017, e indica maior número de produções científicas em 2014.

Como exemplificação de possiveis políticas que impactaram na produção acadêmica no que se refere aos temas permanência e evasão, podemos citar:

- Programa de Apoio a Planos de Reestruturação e Expansão das Universidades Federais (Reuni), através do Decreto $n^{\circ}$ 6.096, de 24 de abril de 2007, com os objetivos de: criar condições para a ampliação do acesso e da permanência na educação superior; assegurar a qualidade por meio de inovações acadêmicas; promover a articulação entre os diferentes níveis de ensino (graduação, pós-graduação, educação básica e educação 
profissional e tecnológica); e, além disso, otimizar o aproveitamento dos recursos humanos e da infraestrutura das instituições federais de educação superior (BRASIL, 2009).

- 0 Programa de Acessibilidade na Educação Superior (Incluir) ${ }^{5}$, criado em 2005, com a finalidade de garantir o acesso pleno de pessoas com deficiência às Instituições Federais de Ensino Superior (IFES). Assim, o Incluir tem como principal objetivo fomentar a criação e a consolidação de núcleos de acessibilidade nas IFES, os quais respondem pela organização de ações institucionais que garantam a integração de pessoas com deficiência à vida acadêmica, eliminando barreiras comportamentais, pedagógicas, arquitetônicas e de comunicação.

- Programa Nacional de Assistência Estudantil (PNAES), criado pelo Decreto n ${ }^{\circ}$ 7.234, de 19 de julho de 2010, e o Programa Nacional de Assistência Estudantil para as Instituições de Educação Superior Públicas Estaduais (PNAEST), por meio da Portaria Normativa $n^{\circ} 25$, de 28 de dezembro de 2010, com os seguintes objetivos: democratizar as condições de permanência dos jovens na educação superior pública federal; minimizar os efeitos das desigualdades sociais e regionais na permanência e na conclusão da educação superior; reduzir as taxas de retenção e evasão; e contribuir para a promoção da inclusão social pela educação (BRASIL, 2010).

A seguir, no Gráfico 3, é exposto o vínculo institucional por região das produções selecionadas.

Gráfico 3 - Número de vínculos institucionais por região

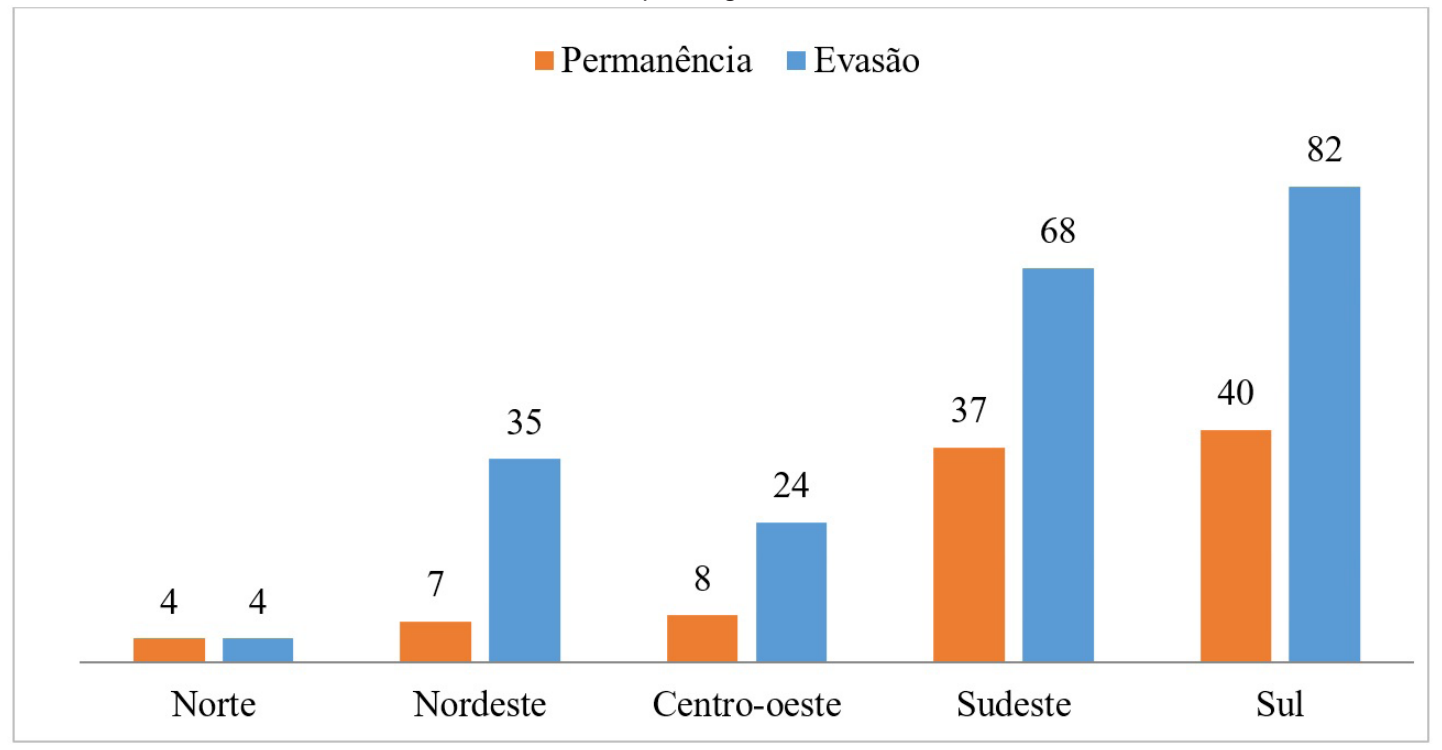

Fonte: SciELO, Grupo de Trabalho 11 da ANPEd, Oasisbr, CAPES/MEC e Domínio Público.

Observa-se que a região Sul do país concentra o maior número de instituições com pesquisadoras/es que estudam permanência e evasão na educação superior,

5- Disponível em: <http://portal.mec.gov.br/programa-incluir/programa-incluir>. Acesso em: 02 abr. 2018. 
correspondendo a 40 trabalhos para permanência e 82 para evasão; em seguida, vêm a região Sudeste, com 37 e 68 trabalhos, respectivamente; a região Nordeste, com 7 e 35; a região Centro-Oeste, com 8 e 24; e, por último, a região Norte, apresentando 4 produções em ambas as categorias.

Cabe destacar que, no caso da região Sul, a IES que concentra o maior número de produções em relação à permanência é a Pontifícia Universidade Católica do Rio Grande do Sul (PUCRS), com oito produções acadêmicas, que estão explicitadas no Quadro 1. Entre estas, três produções estão vinculadas ao Grupo de Pesquisas Redes, Identidades e Subjetividade do Programa de Pós Graduação em Serviço Social/PUCRS (REDIS), uma vinculada ao Grupo de Pesquisa em EAD/PUCRS (ARGOS), uma ao projeto guarda-chuva Rede Sul Brasileira de Investigadores da Educação Superior (RIES) e uma pesquisa vinculada à Rede de Observatórios Sociais de Universidades Católicas da América Latina (RedODSAL).

Quadro 1 - Produções científicas sobre permanência na PUCRS

\begin{tabular}{|l|ccc|}
\hline \multicolumn{1}{|c}{ Autoras/es } & \multicolumn{1}{c}{ Título do trabalho } & Ano & Grupos de \\
pesquisa
\end{tabular}

Fonte: Elaborada pelas/os autoras/es.

Já a IES que concentra o maior número de produções acerca da evasão é a Universidade Federal de Santa Catarina (UFSC), com 22 produções acadêmicas, expostas no Quadro 2. Além do mais, verifica-se que alguns desses trabalhos estão vinculados ao grupo de pesquisa do Instituto de Pesquisas e Estudos em Administração Universitária (INPEAU). A realização de pesquisas em rede consiste em um avanço no sentido da coletividade, envolvendo a produção de conhecimento no país. 
Quadro 2 - Produções científicas sobre evasão na UFSC

\begin{tabular}{|c|c|c|c|}
\hline Autoras/es & Título do trabalho & Ano & $\begin{array}{l}\text { Grupos de } \\
\text { pesquisa }\end{array}$ \\
\hline SOUZA, Irineu Manoel de & $\begin{array}{l}\text { Causas da evasão nos cursos de graduação da Universidade Federal de Santa } \\
\text { Catarina }\end{array}$ & 1999 & - \\
\hline $\begin{array}{l}\text { HOTZA, Maria Aparecida } \\
\text { Silveira }\end{array}$ & $\begin{array}{l}0 \text { abandono nos cursos de graduação da UFSC em 1997: a percepção dos } \\
\text { alunos-abandono }\end{array}$ & 2000 & - \\
\hline $\begin{array}{l}\text { PEREIRA, Fernanda Cristina } \\
\text { Barbosa }\end{array}$ & $\begin{array}{l}\text { Determinantes da evasão de alunos e os custos ocultos para as instituições de } \\
\text { ensino superior: uma aplicação na Universidade do Extremo Sul Catarinense }\end{array}$ & 2003 & - \\
\hline BIAZUS, Cleber Augusto & $\begin{array}{l}\text { Sistema de fatores que influenciam o aluno a evadir-se dos cursos de } \\
\text { graduação na UFSM e na UFSC: um estudo do curso de Ciências Contábeis }\end{array}$ & 2004 & - \\
\hline $\begin{array}{l}\text { NETO, O. A. P.; CRUZ, F.; } \\
\text { PFITSCHER, E. D. }\end{array}$ & $\begin{array}{l}\text { Considerações sobre os riscos da utilização de metas de desempenho ligadas } \\
\text { à taxa de evasão escolar no ensino superior público }\end{array}$ & 2007 & - \\
\hline $\begin{array}{l}\text { PACHECO, Andressa Sasaki } \\
\text { Vasques, et al. }\end{array}$ & Evasão na modalidade a distância & 2007 & INPEAU \\
\hline $\begin{array}{l}\text { PACHECO, Andressa Sasaki } \\
\text { Vasques }\end{array}$ & $\begin{array}{l}\text { Evasão: análise da realidade do curso de graduação em Administração a } \\
\text { distância da Universidade Federal de Santa Catarina }\end{array}$ & 2007 & INPEAU \\
\hline $\begin{array}{l}\text { NETO, O. A. P.; CRUZ, F.; } \\
\text { PFITSCHER, E. D. }\end{array}$ & $\begin{array}{l}\text { Utilização de metas de desempenho ligadas à taxa de evasão } \\
\text { escolar nas universidades públicas }\end{array}$ & 2008 & - \\
\hline COMARELLA, Rafaela Lunardi & Educação superior a distância: evasão discente & 2009 & - \\
\hline $\begin{array}{l}\text { PACHECO, Andressa Sasaki } \\
\text { Vasques }\end{array}$ & $\begin{array}{l}\text { Evasão e permanência dos estudantes de um curso de Administração do } \\
\text { Sistema Universidade Aberta do Brasil: uma teoria fundamentada em fatos e } \\
\text { na gestão do conhecimento }\end{array}$ & 2010 & INPEAU \\
\hline $\begin{array}{l}\text { AZEVEDO, Maria Inês Nava, } \\
\text { et al. }\end{array}$ & $\begin{array}{l}0 \text { acesso à UFSC à luz da teoria da gestão social: uma perspectiva das cotas } \\
\text { e da evasão }\end{array}$ & 2011 & - \\
\hline LIVRAMENTO, Vanessa & $\begin{array}{l}\text { Evasão nos cursos presenciais de graduação da Universidade Federal de } \\
\text { Santa Catarina }\end{array}$ & 2012 & - \\
\hline $\begin{array}{l}\text { BARDAGI, Marucia Patta; } \\
\text { HUTZ, Cláudio Simon }\end{array}$ & $\begin{array}{l}\text { Rotina acadêmica e relação com colegas e professores: impacto na evasão } \\
\text { universitária }\end{array}$ & 2012 & - \\
\hline $\begin{array}{l}\text { MALLMANN, Ana Aparecida } \\
\text { Gomes }\end{array}$ & $\begin{array}{l}\text { Evasão no curso de graduação em Ciências } \\
\text { Econômicas - presencial - da Universidade Federal de Santa Catarina }\end{array}$ & 2013 & INPEAU \\
\hline NAPOLEÃO FILHO, Jair & $\begin{array}{l}\text { Causas para evasão dos alunos do curso de graduação a distância em Ciências } \\
\text { Econômicas da Universidade Federal de Santa Catarina }\end{array}$ & 2013 & INPEAU \\
\hline NAPOLEÃO FILHO, Jair, et al. & $\begin{array}{l}\text { Causas para evasão dos alunos do curso de graduação a distância em } \\
\text { Ciências Econômicas da Universidade Federal de Santa Catarina }\end{array}$ & 2014 & INPEAU \\
\hline $\begin{array}{l}\text { ROSA, Juliana Vaccari de } \\
\text { Abreu da, et al. }\end{array}$ & $\begin{array}{l}\text { Virtualização do ensino superior: um breve diagnóstico da primeira turma do } \\
\text { curso de Administração Pública a distância da UFSC }\end{array}$ & 2014 & - \\
\hline GERBA, Raphael Thiago & $\begin{array}{l}\text { Análise da evasão de alunos nos cursos de licenciatura: estudo de caso no } \\
\text { Instituto Federal de Educação, Ciência e Tecnologia de Santa Catarina }\end{array}$ & 2014 & INPEAU \\
\hline $\begin{array}{l}\text { PACHECO, A. S. V.; NAKAYAMA, } \\
\text { M. K.; RISSI, M. }\end{array}$ & $\begin{array}{l}\text { Evasão e permanência dos estudantes de um curso de Administração a distância } \\
\text { do Sistema Universidade Aberta do Brasil: uma teoria multiparadigmática }\end{array}$ & 2015 & - \\
\hline DIOGO, Maria Fernanda, et al. & $\begin{array}{l}\text { Percepções de coordenadores de curso superior sobre evasão, reprovações e } \\
\text { estratégias preventivas }\end{array}$ & 2016 & INPEAU \\
\hline $\begin{array}{l}\text { SILVA, F. C.; CABRAL, T. L. 0.; } \\
\text { PACHECO, A. S. V. }\end{array}$ & $\begin{array}{l}\text { Evasão em cursos de graduação: uma análise a partir do censo da educação } \\
\text { superior brasileira }\end{array}$ & 2016 & INPEAU \\
\hline SILVA, Fernanda Cristina da & $\begin{array}{l}\text { Gestão da evasão na EAD: modelo estatístico preditivo para os cursos de } \\
\text { graduação a distância da Universidade Federal de Santa Catarina }\end{array}$ & 2017 & \\
\hline
\end{tabular}

Fonte: Elaborada pelas/os autoras/es. 
Quanto às cooperações entre as IES, constata-se que, no caso da temática permanência, oito trabalhos foram produzidos em colaboração com outras IES, seis produções com base na cooperação entre duas IES e duas produções com base na cooperação entre três IES. Já em relação à evasão, três trabalhos foram produzidos com base na cooperação entre duas IES, uma produção com base na cooperação entre três IES e uma produção com base na cooperação entre quatro IES. Nota-se que pesquisas de caráter interinstitucional são incipientes, embora o número de trabalhos acerca da permanência e da evasão na educação superior tenha aumentado nessa última década, como demonstrou o Gráfico 2.

Segundo Veiga (2006, p. 2), “a pesquisa interinstitucional envolve o trabalho em grupo, a parceria, a colaboração. É um processo coletivo de colaboração entre grupos. 0 trabalho investigativo é coletivo, e isto, significa ação conjunta de investigação, de indagação pormenorizada”. Nesse contexto, para a autora, a pesquisa interinstitucional, entre professores/pesquisadores e alunos de graduação e/ou pós-graduação tem surgido como resposta às transformações políticas, sociais, culturais e tecnológicas que colocam em pauta as formas conservadoras e individualistas de produção de conhecimento.

\section{Considerações finais}

0 objetivo deste trabalho foi desvelar as publicações sobre permanência e evasão na educação superior divulgadas como teses, dissertações e artigos. Assim, buscou-se identificar a quantidade de produtos, o ano em que as produções foram desenvolvidas e as instituições onde as pesquisas foram realizadas.

Por meio da consulta em cinco bases de dados - no caso, SciELO, Grupo de Trabalho 11 da ANPEd, Oasisbr, CAPES/MEC e Domínio Público -, constatou-se uma predominância do número de artigos (180), sendo 58 sobre permanência e 122 sobre evasão; seguido por dissertações (97), com 22 sobre permanência e 75 sobre evasão; e, por último, pelas teses (24), com 9 sobre permanência e 15 sobre evasão.

Verificamos, ainda, que a permanência e a evasão apresentam um conjunto extenso de vertentes temáticas. Assim, destacamos que, no caso da permanência, as produções acadêmicas concentram-se em permanência e EaD, permanência e ProUni e permanência e estudantes com deficiência. Já em relação à evasão, os trabalhos estão concentrados em evasão em um conjunto de cursos, evasão na EaD e evasão em um curso de uma instituição específica. No que diz respeito à temática investigada, a $\mathrm{EaD}$ aparece de forma recorrente em relação às duas categorias investigadas.

Outro fator a se considerar refere-se ao ano em que as produções foram desenvolvidas: evidencia-se que os trabalhos sobre permanência tiveram início a partir de 2004, com um crescimento significativo entre os anos de 2012 e 2016. No caso da evasão, verificamos que as produções acadêmicas no Brasil tiveram início em 1977, com um crescimento exponencial entre os anos de 2011 e 2014.

Em relação às instituições onde as pesquisas foram realizadas, a região Sul do país concentra o maior número de produções se comparada às demais regiões do país. Em específico, a PUCRS agrega o maior número de trabalhos relacionados à permanência. Já para evasão, a UFSC contempla o maior número de produções acadêmicas. Além disso, 
nota-se que o número de cooperações interinstitucionais ainda é pequeno, carecendo de mais diálogos entre instituições. Entretanto, é possível identificar a relação das publicações com grupos de pesquisa consolidados e com redes de pesquisa, detalhe que expressa o fortalecimento de pesquisas coletivas que abarcam realidades regionais distintas.

Diante dos dados, conclui-se que a educação superior é pesquisada por meio de diferentes perspectivas, e que a investigação das produções científicas sobre permanência e evasão está relacionada à expansão da educação superior, mas é investigada por meio de diferentes especificidades, como estudos de caso, análise de políticas específicas, entre outras, sempre buscando identificar elementos que determinam a permanência e a evasão nesse nível de educação.

Concluímos que as temáticas investigadas nas produções científicas sobre acesso e permanência na educação superior demonstram que a expansão, nesse nível de educação, teve como parte de suas características a preocupação com esses dois elementos como determinantes do que entendemos como acesso, que se materializa por meio do ingresso, da permanência e da conclusão; assim, a evasão, como destacam as pesquisas analisadas, representa um fenômeno que interfere no acesso e determina fraturas na expansão da educação superior no Brasil.

Os dados deste artigo destacam as temáticas investigadas e relacionadas à permanência e à evasão; acima de tudo, indicam a necessidade de políticas que priorizem os elementos em destaque de forma distinta, mas com igual importância, sendo que um interfere no outro. A evasão de estudantes na educação superior precisa ser compreendida e discutida para que a permanência seja qualificada e preconizada como política e ação indispensável à expansão desse nível de educação.

\section{Referências}

ADACHI, Ana Amélia Chaves Teixeira. Evasão de estudantes de cursos de graduação da USP: ingressantes nos anos de 2002, 2003 e 2004. 2017. Tese (Doutorado em Educação) - Faculdade de Educação, Universidade de São Paulo, São Paulo, 2017.

ADACHI, Ana Amélia Chaves Teixeira. Evasão e evadidos nos cursos de graduação da Universidade Federal de Minas Gerais. 2009. Dissertação (Mestrado em Educação) - Faculdade de Educação, Universidade Federal de Minas Gerais, Belo Horizonte, 2009.

BAGGI, Cristiane Aparecida dos Santos; LOPES, Doraci Alves. Evasão e avaliação institucional no ensino superior: uma discussão bibliográfica. Avaliação, Campinas, v. 16, n. 2, p. 355-374, 2011.

BARDAGI, Marúcia Patta. Evasão e comportamento vocacional de universitários: estudos sobre 0 desenvolvimento de carreira na graduação. 2007. Tese (Doutorado em Psicologia) - Universidade Federal do Rio Grande do Sul, Porto Alegre, 2007.

BARLEM, Jamila Geri Tomaschewski et al. Opção e evasão de um curso de graduação em Enfermagem: percepção de estudantes evadidos. Revista Gaúcha de Enfermagem, Porto Alegre, v. 33, n. 2, p. 132-138, jun. 2012. 
BRAGA, Mauro Mendes; MIRANDA-PINTO, Clotilde O. B. de; CARDEAL, Zenilda de Lourdes. Perfil sócio-econômico dos alunos, repetência e evasão no curso de Química da UFMG. Química Nova, São Paulo, v. 20, n. 4, p. 438-444, 1997.

BRANCO, Ana Paula Silva Cantarelli. Análise das condições de acessibilidade no ensino superior: um estudo com pós-graduandos. 2015. Dissertação (Mestrado em Psicologia) - Universidade Estadual Paulista "Júlio de Mesquita Filho", Bauru, 2015.

BRASIL. Decreto n 7.234, de 19 de julho de 2010. Dispõe sobre o Programa Nacional de Assistência Estudantil (PNAES). Diário Oficial da União, Brasília, DF, 20 jul. 2010. Disponível em: <http://www.planalto. gov.br/ccivil_03/_Ato2007-2010/2010/Decreto/D7234.htm>. Acesso em: 05 jul. 2017.

BRASIL. Lei n 12.711, de 29 de agosto de 2012. Lei das Cotas. Brasília, DF: Casa Civil, 2012. Disponível em: <http://www.planalto.gov.br/ccivil_03/_at02011-2014/2012/lei/l12711.htm>. Acesso em: 05 jul. 2017.

BRASIL. Portaria $n^{0}$ 25, de 28 de dezembro de 2010. Dispõe sobre o Programa Nacional de Assistência Estudantil para as instituições de educação superior públicas estaduais (PNAEST). Brasília, DF: MEC, 2010. Disponível em: <http://www.uel.br/prograd/eventos/enem/documentos/portaria_mec_25_28.12.2010. pdf>. Acesso em: 26 jun. 2019.

BRASIL. Ministério da Educação. Programa de apoio a planos de Reestruturação e Expansão das Universidades Federais (REUNI) 2008: Relatório do primeiro ano. Brasília, DF: MEC, 2009.

BRASIL. Ministério da Educação. Secretaria de Educação Superior. Comissão Especial de Estudos sobre a Evasão nas Universidades Públicas Brasileiras. Diplomação, retenção e evasão nos cursos de graduação em instituições de ensino superior públicas. Brasilia, DF: ANDIFES/ABRUEM/SESu/MEC, 1996.

BUENO, José Lino Oliveira. A evasão de alunos. Paidéia, Ribeirão Preto, n. 5, p. 9-16, ago. 1993.

BUENO, Rita de Cássia Soares de Souza. Políticas públicas na educação superior: as ações de permanência para estudantes cotistas no programa de ações afirmativas da UFRGS. 2015. Dissertação (Mestrado em Educação) - Universidade Federal do Rio Grande do Sul, Porto Alegre, 2015.

CASTRO, Sabrina Fernandes de; ALMEIDA, Maria Amelia. Ingresso e permanência de alunos com deficiência em universidades públicas brasileiras. Revista Brasileira de Educação Especial, Marília, v. 20, n. 2, p. 179194, abr./jun. 2014.

CAVALCANTE, Maria Cleide Lima Pereira. Políticas de educação superior: acesso e permanência de estudantes trabalhadores dos cursos noturnos (1996-2006). 2008. Dissertação (Mestrado em Educação) - Universidade Católica Dom Bosco, Campo Grande, 2008.

COULON, Alain. A condição de estudante: a entrada na vida universitária. Tradução de Georgina Gonçalves dos Santos e Sônia Maria Rocha Sampaio. Salvador: Edufba, 2008. Título original: Le métier d'etudiant: l'entrée dans la vie universitaire. 
FERREIRA, Norma Sandra de Almeida. As pesquisas denominadas "Estado da Arte". Educação \& Sociedade, Campinas, v. 23, n. 79, p. 254-272, ago. 2002.

FIUZA, Patricia Jantsch; SARRIERA, Jorge Castellá. Motivos para adesão e permanência discente na educação superior a distância. Psicologia, Ciência e Profissão, Porto Alegre, n. 33, p. 884-901, 2013.

FREITAS, Rafael Scarassatti. A ocorrência da evasão no ensino superior: uma análise das diferentes formas de mensurar. 2016. Dissertação (Mestrado em Educação) - Faculdade de Educação, Universidade Estadual de Campinas, Campinas, 2016.

INEP. instituto nacional de estudos e pesquisas educacionais anísio teixeira. Sinopse estatística da educação superior (1995-2017). Brasília, DF: INEP, 2018. Disponível em: <http://inep.gov.br/web/guest/sinopsesestatisticas-da-educacao-superior>. Acesso em: 22 set. 2018.

LAVARDA, Eliane Sperandei. 0 currículo e a inclusão na educação superior: ações de permanência nos cursos de graduação da UFSM. Dissertação (Mestrado em Educação) - Universidade Federal de Santa Maria, Santa Maria, 2014.

MACIEL, Carina Elisabeth; LIMA, Elizeth Gonzaga dos Santos; GIMENEZ, Felipe Vieira. Políticas e permanência para estudantes na educação superior. Revista Brasileira de Política e Administração da Educação, Goiânia, v. 32, n. 3, p. 759-781, set./dez. 2016.

MELLO, Simone Portella Teixeira de; SANTOS, Elaine Garcia dos. Diagnóstico e alternativas de contenção da evasão no curso de Administração em uma universidade pública no Sul do Brasil. GUAL, Florianópolis, v. 5, n. 3, p. 67-80, dez. 2012.

MINAYO, Maria Cecília de Souza (Org.). Pesquisa social: teoria, método e criatividade. Petrópolis: Vozes, 2016. (Manuais acadêmicos).

MOROSINI, Marília Costa et al. A evasão na educação superior no Brasil: uma análise da produção de conhecimento nos periódicos qualis entre 2000-2011. In: CONFERENCIA LATINOAMERICANA SOBRE EL ABANDONO EN LA EDUCACIÓN SUPERIOR, 2., 2012, Managua-Nicaragua. Anais... Managua: Clabes, 2012. p. 1-10.

PALMA, Simone Poch Vieira. Experiências de evasão de um curso de psicologia. 2007. Dissertação (Mestrado em Psicologia) - Faculdade de Filosofia, Ciências e Letras de Ribeirão Preto, Universidade de São Paulo, Ribeirão Preto, 2007.

PASSOS, Joana Célia dos. Relações raciais, cultura acadêmica e tensionamentos após ações afirmativas. Educação em Revista, Belo Horizonte, v. 31, n. 02, p. 155-182, abr./jun. 2015.

PEREIRA JUNIOR, Edgar. Compromisso com o graduar-se, com a instituição e com o curso: estrutura fatorial e relação com a evasão. 2012. Dissertação (Mestrado em Educação) - Faculdade de Educação, Universidade Estadual de Campinas, Campinas, 2012. 
POLYDORO, Soely Aparecida Jorge. 0 trancamento de matrícula na trajetória acadêmica do universitário: condições de saída e de retorno à instituição. 2000. Tese (Doutorado em Educação) - Faculdade de Educação, Universidade Estadual de Campinas, Campinas, 2000.

SANTOS, Dyane Brito Reis. Para além das cotas: a permanência de estudantes negros no ensino superior como política de ação afirmativa. 2009. Tese (Doutorado em Educação) - Universidade Federal da Bahia, Salvador, 2009.

SANTOS, Flávio Correia Santos. As disciplinas de exatas e o processo de ensino para alunos com deficiência visual na Universidade Federal de Sergipe. 2014. Dissertação (Mestrado em Ensino de Ciências e Matemática) - Universidade Federal de Sergipe, São Cristovão, 2014.

SANTOS, Marianna Luiza Alves. Itinerários universitários: a permanência de mães trabalhadoras nos bacharelados interdisciplinares da Universidade Federal da Bahia. 2014. Dissertação (Mestrado em Estudos Interdisciplinares Sobre a Universidade) - Universidade Federal da Bahia, Salvador, 2014.

SCALI, Danyelle Freitas. Evasão nos cursos superiores de tecnologia: a percepção dos estudantes sobre seus determinantes. 2009. Dissertação (Mestrado em Educação) - Faculdade de Educação, Universidade Estadual de Campinas, Campinas, 2009.

SENA, Eni de Faria. Estímulo, acesso, permanência e conclusão no ensino superior de alunos bolsistas do Programa Universidade para Todos (PROUNI): contribuições para o enfrentamento do processo de inserção. 2011. Tese (Doutorado em Educação) - Pontifícia Universidade Católica de São Paulo, São Paulo, 2011.

SILVA, Fernanda Cristina da. Gestão da evasão na EAD: modelo estatístico preditivo para os cursos de graduação a distância da Universidade Federal de Santa Catarina. 2017. Dissertação (Mestrado em Administração) - Universidade Federal de Santa Catarina, Florianópolis, 2017.

SILVA, Francisca Islandia Cardoso da et al. Evasão escolar no curso de educação física da Universidade Federal do Piauí. Avaliação, Campinas, v. 17, n. 2, p. 391-404, jul. 2012.

SILVA, João Augusto Ramos. Permanência de alunos nos cursos presenciais e a distância em administração: contribuições para a gestão acadêmica. 2012. Tese (Doutorado em Administração) - Fundação Getúlio Vargas, Rio de Janeiro, 2012.

SILVA, Marilene de Almeida Viana Reid. A evasão da UENF: uma análise dos cursos de licenciatura (20032007). 2009. Dissertação (Mestrado em Políticas Sociais) - Universidade Estadual do Norte Fluminense Darcy Ribeiro, Campos dos Goytacazes, 2009.

TIBOLA, Jucelia Appio. Antecedentes da lealdade e da permanência de alunos em uma instituição de ensino superior. 2010. Dissertação (Mestrado em Administração) - Universidade Regional de Blumenau, Blumenau, 2010.

VEIGA, IIma Passos Alencastro. A pesquisa interinstitucional: um horizonte de possibilidades formativas. In: REUNIÃO ANUAL DA ASSOCIAÇÃO NACIONAL DE PÓS-GRADUAÇÃO E PESQUISA EM EDUCAÇÃO, 29., 2006, Caxambu. Anais... Caxambu: ANPEd, 2006. p. 1-11. 
ZAGO, Nadir. Do acesso à permanência no ensino superior: percurso de estudantes universitários de camadas populares. Revista Brasileira de Educação, Rio de Janeiro, v. 11, n. 32, p. 226-238, maio/ago. 2006.

Recebido em: 11.05 .2018

Revisado em: 26.09.2018

Aprovado em: 06.11.2018

Carina Elisabeth Maciel é pós-doutora em educação pela Universidade do Estado de Mato Grosso (UNEMAT, 2016), doutora em educação pela Universidade Federal de Mato Grosso do Sul (UFMS, 2009) e mestra em educação pela Universidade Católica Dom Bosco (UCDB, 2005). É docente da UFMS e coordenadora do Grupo de Estudos e Pesquisas em Políticas de Educação Superior / Mariluce Bittar (GEPPES/MB).

Mauro Cunha Júnior é graduado em ciências sociais pela Universidade Federal de Mato Grosso do Sul (UFMS, 2017) e mestrando em educação pela mesma instituição. É membro do Grupo de Estudos e Pesquisas em Políticas de Educação Superior / Mariluce Bittar (GEPPES/MB).

Tatiane da Silva Lima é graduada em pedagogia pela Universidade Federal de Mato Grosso do Sul (UFMS, 2017) e mestranda em educação pela mesma instituição. É membro do Grupo de Estudos e Pesquisas em Políticas de Educação Superior / Mariluce Bittar (GEPPES/MB). 